\title{
Acute Respiratory Failure Secondary to ACE Inhibitor-Induced Angioedema after Five Years of Lisinopril Therapy
}

\author{
Tariq Sharman*, Jeffrey Song, Misam Zawit, Una Ijeoma-Nchinda \\ Department of Medicine, Heritage College of Osteopathic Medicine, \\ Southern Ohio Medical Center, Ohio University, Portsmouth, Ohio, USA \\ *Corresponding author: tysharman@yahoo.com
}

Received October 01, 2019; Revised November 04, 2019; Accepted November 12, 2019

\begin{abstract}
Angiotensin-converting enzyme (ACE) inhibitors are amongst the commonest prescribed medications in the United States and considered to be the leading causes of drug induced angioedema. High bradykinin levels stimulate vasodilation and increased vascular permeability of the post-capillary venules and allow for plasma extravasation into the submucosal tissue, leading to angioedema. Usually, the angioedema occurs within the first week of exposure to therapy, but cases occurring after years of stable ACE inhibitor usage are not uncommon. Here, we present a 43-year-old Caucasian female who developed acute respiratory failure requiring mechanical ventilation secondary to ACEi-induced angioedema after five years of Lisinopril usage. This case will help to increase physicians' awareness that this potentially fatal complication can still occur after years of ACE inhibitor usage.
\end{abstract}

Keywords: Angioedema, Angiotensin converting enzyme inhibitor, Bradykinin, des-Arg9-BK, Complement, C4, substance $P, A C E$

Cite This Article: Tariq Sharman, Jeffrey Song, Misam Zawit, and Una Ijeoma-Nchinda, "Acute Respiratory Failure Secondary to ACE Inhibitor-Induced Angioedema after Five Years of Lisinopril Therapy.” American Journal of Medical Case Reports, vol. 8, no. 1 (2020): 8-10. doi: 10.12691/ajmcr-8-1-2.

\section{Introduction}

Angiotensin-converting enzyme (ACE) inhibitors are commonly prescribed medications in the United States and considered to be the leading cause of drug induced angioedema.

Angioedema is an area of swelling of the lower layer of skin and tissue just underneath the skin or mucous membranes. The swelling may occur in the face, tongue, larynx, abdomen, arms and legs. The onset is typically over minutes to hours. In ACE inhibitor-induced angioedema, there is usually an absence of itching or urticaria. In fact, the presence of urticaria suggests a different group of etiologies. ACE inhibitors block the effects of the angiotensin-converting enzyme. ACE (kininase II) is the primary peptidase in the degradation of bradykinin. Bradykinin is a peptide that increases capillary permeability and acts as a potent vasodilator. ACE inhibitor therapy affects the patient by causing vasodilation by inhibiting the production of angiotensin II and increasing the bradykinin levels due to impaired metabolism. As a result, high bradykinin levels stimulate vasodilation and increased vascular permeability of the post-capillary venules and allow for plasma extravasation into the submucosal tissue, leading to angioedema.
This case discusses a patient who developed acute respiratory failure requiring intubation and mechanical ventilation secondary to ACEi -induced angioedema after 5 years of being treated with Lisinopril for hypertension, highlighting the fact that this fatal side effect can still occur years after being on an ACE inhibitor.

\section{Case Presentation}

The patient is a 43-year-old Caucasian female with medical history significant for diabetes mellitus type 2, hypertension, generalized anxiety disorder and nonalcoholic steatohepatitis, who presented to the emergency room (ER) with complaints of tongue swelling, difficulty swallowing and shortness of breath shortly after taking her regular daily medications on the morning of her presentation. She denied any chest pain, nausea, vomiting, abdominal pain, diarrhea, itching or skin rash. She denied any sexual intercourse before the onset of her symptoms. She denied any exposure to new food, new medications, new chemical materials or noxious gases. She denied any history of lung diseases. She denied any previous episodes of angioedema or any family history of similar incidents. She denied any recent changes in her medications or taking over-the-counter medications or herbal supplements. Her medications included Lisinopril $20 \mathrm{mg}$ in am and $10 \mathrm{mg}$ in pm orally, Liraglutide $1.8 \mathrm{mg}$ 
subcutaneous injection daily and Citalopram $40 \mathrm{mg}$ oral tablet daily. She has been taking Lisinopril for hypertension for the last 5 years and the last dose adjustment was one year ago.

On arrival to the ER, her vital signs showed blood pressure of $137 / 100 \mathrm{mmHg}$, heart rate of 109 beats per minute, respiratory rate of 24 breaths per minute, temperature of $98.9 \mathrm{~F}$ and oxygen saturation of $92 \%$ on room air. Head and neck examination revealed a swollen tongue and lips with uvular edema. Cardiovascular examination revealed tachycardia with audible S1 and S2 with no murmurs. Respiratory examination revealed scatted wheezes. Shortly after her arrival, her heart rate increased to 129 beats per minute. She became more tachypneic and more distressed. She was requiring $3 \mathrm{~L}$ of oxygen via nasal cannula to keep her saturation around $90 \%$. The patient was given epinephrine intramuscularly twice in addition to intravenous methylprednisolone and intravenous diphenhydramine. However, her shortness of breath and angioedema worsened rapidly, so she was intubated and mechanically ventilated. Laboratory and imaging studies were sent. Her chest X-ray showed perihilar congestive changes and right apical infiltrate. Laboratory work up revealed a normal complete blood count, normal complete metabolic profile, erythrocyte sedimentation rate $44 \mathrm{~mm} / \mathrm{hr}$ and lactic acid of $4 \mathrm{mg} / \mathrm{dL}$. Procalcitonin was $0.05 \mathrm{ng} / \mathrm{mL}$. Her C4 Complement level of $25.9 \mathrm{mg} / \mathrm{dL}$ (Within Normal Range). C1Q complement of $73 \mathrm{U} / \mathrm{mL}$. The Arterial blood gas on mechanical ventilation showed (PH of 7.32 , $\mathrm{CO} 2$ : $50 \mathrm{mmHg}, \mathrm{PO} 2$ : $108 \mathrm{mmHg}$ ) on $40 \% \mathrm{FiO} 2$. She was admitted to the intensive care unit and started on ampicillin/sulbactam due to the possibility of aspiration. We continued the bronchodilators, intravenous steroids and intravenous H1 and $\mathrm{H} 2$ blockers to help decrease the swelling. She subsequently improved and was successfully extubated next day. Lisinopril was discontinued and ACE inhibitors were added to her allergy profile. She was also counseled on avoidance of ACE inhibitors in the future.

\section{Discussion}

Angiotensin converting enzyme inhibitors (ACEi) are widely prescribed in the USA. ACEi - induced angioedema occurs in $0.1 \%$ to $0.7 \%$ of ACEi users [1,2]. ACE inhibitors are among the leading causes of druginduced angioedema in the United States in addition to Non-Steroidal Anti-Inflammatory Drugs.

Angioedema is a non-pitting swelling of the subcutaneous or submucosal tissues commonly affects nondependent areas mainly lips, tongue, face, pharynx, larynx, and subglottic area [3]. Throat swelling, tongue swelling and inspiratory stridor may progress to life threatening upper airway obstruction $[4,5]$. Other systemic manifestations of ACEi-induced angioedema include diffuse abdominal pain, diarrhea, vomiting, anorexia and ascites secondary to visceral involvement. The jejunum is most often involved, followed by the ileum and duodenum $[6,7,8,9]$, though involvement of the stomach has been reported as well [10].

ACE inhibitor-induced angioedema usually develops over minutes to hours and then resolves over 24 to 72 hours, however, complete resolution may take days in some cases. Usually, the angioedema occurs within the first week of exposure to therapy [2,11,12]. However, there have been multiple reports of cases occurring after years of stable ACEi usage as in our patient [13,14,15]. In most cases, the episode of angioedema is mild and resolves without complications. However, endotracheal intubation or emergency tracheostomy may be necessary for angioedema that obstructs the upper airways.

The hypothesized mechanism of ACEi induced angioedema involves the blockade of the enzyme ACE which impacts both the renin-angiotensin-aldosterone (RAA) pathway and the degradation of bradykinin. The RAA cascade is important in regulating renal blood flow and blood pressure. Angiotensinogen is produced in the liver and is converted by renin in the kidneys to produce angiotensin I. Angiotensin I is then metabolized to angiotensin II in the lungs by the enzyme ACE. Angiotensin II acts as a vasoconstrictor through stimulation of angiotensin I and II receptors. ACE is the primary enzyme involved in the degradation of bradykinin in addition to Angiotensin II which also plays a role in inactivating bradykinin. Bradykinin levels become elevated due to impaired metabolism, which leads to release of nitric oxide and prostaglandins and results in vasodilatation and hypotension [16]. In addition, the inhibition of the production of angiotensin II also causes vasodilation. The high levels of bradykinin cause vasodilation and increase vascular permeability of the post-capillary venules thereby allowing for plasma extravasation into the submucosal tissue, leading to angioedema $[17,18]$. Other metabolites playing roles in ACEi-induced angioedema include des-Arg9-BK, and substance P $[19,20]$. Substance $\mathrm{P}$ is a potent vasodilator that can cause vasodilatation via nitric oxide release. Abnormality of the endogenous des-Arg(9)-BK degradation exists in the plasma of patients with ACEi-associated angioedema, suggesting that its pathogenetic mechanism lies in the catabolic site of kinin metabolism.

The diagnosis of ACE inhibitor-induced angioedema is usually clinical, based on the presence of angioedema, without itching or urticaria in a patient who takes ACE inhibitors. No laboratory tests to diagnose ACE inhibitorinduced angioedema is needed. However, complement protein 4 (C4) can be sent if there is a suspicion for other rare angioedema disorders in the setting of positive family history of angioedema or underlying lymphoproliferative disorder. A low C4 should prompt a more complete laboratory evaluation, including C1 inhibitor function and protein levels, C4 level, and C1q levels. When visceral involvement is suspected, ultrasonography and computed tomography of the abdomen can be obtained. Usually the typical findings will include dilated bowel loops, a "stacked coin" or "doughnut" appearance, mesenteric edema, thickened mucosal folds, and possible ascites [22,23].

Multiple risk factors have shown to increase the risk of ACE inhibitor-induced angioedema including previous episodes of angioedema, seasonal allergies, previous NSAIDs related angioedema, smoking and female sex [24,25].

The treatments of ACE inhibitor-induced angioedema are acute airway management if the mouth or throat is involved and discontinuation of the offending drug. Glucocorticoids have been shown to induce the expression 
of ACE [26] and could theoretically accelerate bradykinin metabolism and thus alleviate angioedema that is mediated by bradykinin. Because ACEI-induced angioedema is not a histamine-mediated process, the role of antihistamines is unclear, and they usually have minimal response. Steroids and antihistamines can be used empirically at first presentation when the angioedema is severe and the etiology is not yet clear. After an episode of ACE inhibitor-induced angioedema, it is imperative that ACE inhibitors be never used again.

\section{Conclusion}

ACE inhibitor-induced angioedema is the leading cause of angioedema in the USA. The reaction usually occurs within the first week of initiating therapy. However, it can still occur after years of stable ACE inhibitor usage. Upper airway compromise is the most feared complication, but visceral involvement is not uncommon and can be evaluated with ultrasonography and computed tomography. Clinicians are advised to be wary of ACE inhibitor induced angioedema even after several years of ACEi usage.

\section{Statement of Ethics}

Written consent to publish this case report was obtained from the patient.

\section{Disclosure Statement}

The authors have no conflicts of interest to declare.

\section{Funding Sources}

The authors have no funding sources to disclose.

\section{References}

[1] Banerji A, Blumenthal KG, Lai KH, Zhou L. Epidemiology of ACE Inhibitor Angioedema Utilizing a Large Electronic Health Record. J Allergy Clin Immunol Pract. 2017.

[2] Makani H, Messerli FH, Romero J, Wever-Pinzon O, Korniyenko A, Berrios RS, Bangalore S. Meta-analysis of randomized trials of angioedema as an adverse event of renin-angiotensin system inhibitors. Am J Cardiol. 2012 Aug; 110(3): 383-91. Epub 2012 Apr 20.

[3] Kaplan AP, Greaves MW. Angioedema. J Am Acad Dermatol. 2005; 53(3): 373.

[4] Banerji A, Clark S, Blanda M, LoVecchio F, Snyder B, Camargo CA Jr. Multicenter study of patients with angiotensin-converting enzyme inhibitor-induced angioedema who present to the emergency department. Ann Allergy Asthma Immunol. 2008; 100(4): 327.

[5] Grant NN, Deeb ZE, Chia SH. Clinical experience with angiotensin-converting enzyme inhibitor-induced angioedema. Otolaryngol Head Neck Surg. 2007 Dec; 137(6): 931-5.
[6] Schmidt TD, McGrath KM. Angiotensin-converting enzyme inhibitor angioedema of the intestine: a case report and review of the literature. Am J Med Sci. 2002; 324(2): 106.

[7] Marmery H, Mirvis SE. Angiotensin-converting enzyme inhibitorinduced visceral angioedema. Clin Radiol. 2006 Nov; 61(11): 979-82.

[8] Oudit G, Girgrah N, Allard J. ACE inhibitor-induced angioedema of the intestine: Case report, incidence, pathophysiology, diagnosis and management. Can J Gastroenterol. 2001; 15(12): 827. Am J Gastroenterol. 1993; 88(3): 436.

[9] Eck SL, Morse JH, Janssen DA, Emerson SG, Markovitz DM. Angioedema presenting as chronic gastrointestinal symptoms. Am J Gastroenterol. 1993; 88(3): 436.

[10] Korniyenko A, Alviar CL, Cordova JP, Messerli FH. Visceral angioedema due to angiotensin-converting enzyme inhibitor therapy. Cleve Clin J Med. 2011; 78(5): 297.

[11] Malde B, Regalado J, Greenberger PA. Investigation of angioedema associated with the use of angiotensin-converting enzyme inhibitors and angiotensin receptor blockers. Ann Allergy Asthma Immunol. 2007; 98(1): 57.

[12] Sabroe RA, Black AK. Angiotensin-converting enzyme (ACE) inhibitors and angio-oedema. Br J Dermatol. 1997; 136(2): 153.

[13] Brown NJ, Snowden M, Griffin MR. Recurrent angiotensinconverting enzyme inhibitor--associated angioedema. JAMA. 1997; 278(3): 232.

[14] Bas M, Adams V, Suvorava T, Niehues T, Hoffmann TK, Kojda G. Nonallergic angioedema: role of bradykinin. Allergy. 2007; 62(8): 842.

[15] Nishad AAN, Arulmoly K, Priyankara SAS, Abeysundara PK. A Forgotten Cause of Allergy at ER That Is Still Difficult to Diagnose and Treat at Poor Resource Setting: Angioedema after Using Angiotensin Converting Enzyme Inhibitors for 4 Years. Case Reports Immunol. 2019 Jan 2; 2019: 1676391.

[16] Marceau F, Hess JF, Bachvarov DR. The B1 receptors for kinins. Pharmacol Rev. 1998 Sep; 50(3): 357-86.

[17] Nussberger J, Cugno M, Amstutz C, Cicardi M, Pellacani A, Agostoni A. Plasma bradykinin in angio-oedema. Lancet. 1998; 351(9117): 1693.

[18] Kaplan AP, Ghebrehiwet B. The plasma bradykinin-forming pathways and its interrelationships with complement. Mol Immunol. 2010; 47(13): 2161.

[19] Emanueli C, Grady EF, Madeddu P, Figini M, Bunnett NW, Parisi D, Regoli D, Geppetti P. Acute ACE inhibition causes plasma extravasation in mice that is mediated by bradykinin and substance P. Hypertension. 1998; 31(6): 1299.

[20] Byrd JB, Adam A, Brown NJ. Angiotensin-converting enzyme inhibitor-associated angioedema. Immunol Allergy Clin North Am. 2006 Nov; 26(4):725-37.

[21] Molinaro G, Cugno M, Perez M, Lepage Y, Gervais N, Agostoni A, Adam A. Angiotensin-converting enzyme inhibitor-associated angioedema is characterized by a slower degradation of desarginine(9)-bradykinin. J Pharmacol Exp Ther. 2002 Oct; 303(1): 232-7.

[22] Ciaccia D, Brazer SR, Baker ME. Acquired C1 esterase inhibitor deficiency causing intestinal angioedema: CT appearance. AJR Am J Roentgenol. 1993 Dec; 161(6): 1215-6.

[23] Marmery H, Mirvis SE. Angiotensin-converting enzyme inhibitor-induced visceral angioedema. Clin Radiol. 2006 Nov; 61(11): 979-82.

[24] Kostis JB, Kim HJ, Rusnak J, Casale T, Kaplan A, Corren J, Levy E. Incidence and characteristics of angioedema associated with enalapril. Arch Intern Med. 2005; 165(14): 1637.

[25] Hoover T, Lippmann M, Grouzmann E, Marceau F, Herscu P. Angiotensin converting enzyme inhibitor induced angio-oedema: a review of the pathophysiology and risk factors. Clin Exp Allergy. 2010 Jan; 40(1): 50-61.

[26] Y. Dasarathy, J. J. Lanzillo, and B. L. Fanburg. Stimulation of bovine pulmonary artery endothelial cell ACE by dexamethasone: involvement of steroid receptors. Am J Physiol. 1992 Dec; 263(6 Pt 1): L645-9. 